\title{
Article
}

\section{A Review of the Geomechanics Aspects in Space Exploration}

\author{
Dariusz Knez * (D) and Mohammad Ahmad Mahmoudi Zamani (D) \\ Department of Drilling and Geoengineering, Faculty of Drilling, Oil and Gas, AGH University of Science \\ and Technology, 30-059 Krakow, Poland; zamani@agh.edu.pl \\ * Correspondence: knez@agh.edu.pl
}

check for updates

Citation: Knez, D.; Zamani, M.A.M. A Review of the Geomechanics Aspects in Space Exploration. Energies 2021, 14, 7522. https://doi.org/ $10.3390 /$ en14227522

Academic Editors: Mohammad

Vahab, Omid Ghasemi-Fare and Babak Shahbodagh

Received: 18 October 2021

Accepted: 7 November 2021

Published: 11 November 2021

Publisher's Note: MDPI stays neutral with regard to jurisdictional claims in published maps and institutional affiliations.

Copyright: (C) 2021 by the authors. Licensee MDPI, Basel, Switzerland. This article is an open access article distributed under the terms and conditions of the Creative Commons Attribution (CC BY) license (https:// creativecommons.org/licenses/by/ $4.0 /)$.

\begin{abstract}
From the 2000s onwards, unprecedented space missions have brought about a wealth of novel investigations on the different aspects of space geomechanics. Such aspects are related to the exploratory activities such as drilling, sampling, coring, water extraction, anchoring, etc. So far, a whole range of constitutive research projects on the plate tectonics, morphology, volcanic activities and volatile content of planetary bodies have been implemented. Furthermore, various laboratory experiments on extraterrestrial samples and their artificial terrestrial simulants are continually conducted to obtain the physical and mechanical properties of the corresponding specimens. Today, with the space boom being steered by diverse space agencies, the incorporation of geomechanics into space exploration appreciably appears much needed. The primary objective of this article is to collate and integrate the up-to-date investigations related to the geomechanical applications in space technologies. Emphasis is given to the new and future applications such as planetary drilling and water extraction. The main impetus is to provide a comprehensive reference for geoscience scientists and astronauts to quickly become acquainted with the cutting-edge advancements in the area of space geomechanics. Moreover, this research study also elaborates on the operational constraints in space geomechanics which necessitate further scientific investigations.
\end{abstract}

Keywords: drilling; water extraction; regolith; planetary bodies; space exploration; Moon; Mars; tectonics; anchoring; TBM

\section{Introduction}

The early era of space exploration started in 1957 when two artificial spacecrafts, Sputnik 1 and Sputnik 2, were launched into the space by the Soviet Union. In 1958, the US initiated its space missions by launching the Explorer 1 satellite. From that time, there has been a wide range of spaceflights and space missions to explore the different features of planetary bodies, especially the Moon and Mars.

From a geomechanics standpoint, it can be said that the first investigation was conducted for the sampling of the lunar regolith by the Luna 9 space probe in February 1966 [1]. This space probe successfully landed on the Moon's surface and measured a set of physical properties of the lunar top regolith. Before that time, the estimations of the physical properties of the lunar soil were based on astronomical and radio-physical investigations [1]. In the same year, Luna 10, Luna 11 and Luna 12 were launched into the Earth's orbit and recorded the $X$-radiation and gamma-radiation reflected by the lunar surface. A comparison of those radiation spectra with Earth's rocks illustrated that the lunar soil's composition was identical to that of basaltic rocks. This was the first outstanding achievement in the branch of space geomechanics.

From that date onwards, many artificial terrestrial analogues, such as basaltic volcanic ash and sand admixtures, have been synthesized to provide artificial simulants for the conduction of various geomechanical tests. Consequently, the laboratory experiments brought about a better comprehension of the potential properties of lunar soils. Viking 1 was the first spacecraft that successfully landed on Mars in 1975. Regarding Mars, the data acquired by the remote sensing and new investigations have demonstrated that the 
Martian regolith possesses a basaltic composition [2]. Furthermore, in February 2006, the Opportunity rover detected some sediments such as sandstone rocks on the Martian surface. In this article, an expansive description of the geological conditions of the Moon and Mars is recounted.

As other investigations acquired more knowledge about the lunar and Martian regolith, scientists came up with the idea of the building permanent habitats (outposts) on the Moon's and Mars' surfaces. They contemplated developing the surface outposts to shelter the astronauts from space radiations, meteorite collisions and extreme temperature fluctuations. Detailed descriptions of such environmentally harsh conditions can be found in [3-5]. So far, plenty of different layouts of outposts have been conceptualized by construction professionals and civil engineers [6-16]; however, the description of their details is out of the scope of this article. The main geomechanical aspect of building such non-terrestrial structures is the crucial requirement for the foundation installment. Without a strong foundation, the structure cannot be consistently stable on the site due to the microgravity effect on the lunar and Martian surfaces. The gravitational acceleration on the Moon's and Mars' surfaces is respectively equal to $1.62 \mathrm{~m} / \mathrm{s}^{2}$ and $3.71 \mathrm{~m} / \mathrm{s}^{2}$, compared to the $9.81 \mathrm{~m} / \mathrm{s}^{2}$ on Earth. To address this challenge, an anchoring technique was put forward as a conceivably reliable solution for overcoming the microgravity impact [17-20]. Anchoring techniques aside, the usage of regolith-fabricated pads for facilitating the landing and takeoff operations of the spaceflights is another novel idea in the development of outposts. Present-day investigations on the anchoring technique and landing/takeoff pads are discussed in the subsequent parts of this research paper.

The knowledge about the lunar and Martian regoliths' properties is principally restricted to the surface and to shallow samples (less than a few centimeters). However, it seems that every future plan, such as the construction of outposts, requires adequate extra information about what lies underneath. Currently, the drilling technology is presumably conceived as the most practical utilization of geomechanics in space exploration. Drilling can satisfy a wide spectrum of pre-requisites for different applications on planetary surfaces. Those applications comprise outposts' construction, anchor installment, coring, space mining, water extraction, underground tunneling, etc. A large number of different drilling techniques and machines have been conceptualized and assembled so far [21-23]. Their penetration rate is examined through drilling tests conducted in the terrestrial analogues.

Space drilling not only relies on the physical and mechanical properties of the lunar and Martian regolith but it is also governed by the forces and faults which are active in the Moon's and Mars' lithospheres. In the case of Earth, the sub-crustal stress is linked to the global tectonics that stems from mantle convection. Nevertheless, the magnitude and the origin of the tectonics on the two planetary bodies appear to be dissimilar. On Mars, active tectonics is limited to some regional parts and is ascribed to the volcanic activities within the planet [24]. Tenzer and Eshagh, in [25], utilized the model introduced by [26] to calculate both crustal thickness and the sub-crustal stress state within Mars. They discovered that the most sub-crustal stress is present in the Tharsis area of Mars and is rooted in the volcanic activities. Moreover, they also discovered that the meteorite impacts on some parts of the region have intensified the stress state around the craters, thereby causing localized stress anomalies. The presence of large thrust faults in the Moon's and Mars' crusts has been corroborated by the new photographs provided by recent spaceflights. The main origin of the prominent landforms on Mars has been ascribed to the existence of such thrust faults within the Martian crust [27-29]. The size and dimensions of such landforms were partially deployed to estimate the length and the dip of the corresponding surface-breaking faults [30-34]. For instance, in the case of the Amenthes Rupes landform, which has a length of $420 \mathrm{~km}$, the numerical simulation has anticipated an underlying fault with a length between $30 \mathrm{~km}$ [30] and $48 \mathrm{~km}$ [34].

Once the essential data, including the physical and mechanical characteristics of the regolith together with the regional active stress field, were ascertained, a comprehensive plan could be devised for drilling the lunar or Martian rocks. Space drilling programs have 
absorbed an increasingly global attention to execute a raft of missions on close and remote celestial bodies. Those missions track extensive objectives; hence, the type of drilling operation may vary from one case to another. Overall, space drilling can be subdivided into two broad categories, including surficial and subsurface drilling.

Surficial drilling can be remarkably deployed in exploratory programs with aims such as the determination of the mineralogy and the volatile content of a certain region. Volatile content refers to different gases or vital minerals, such as CHNOPS (Carbon, Hydrogen, Nitrogen, Oxigen, Posphor and Sulphur), water, etc. Exploratory drilling can appreciably contribute to the space agencies' missions for different purposes. For instance, when the target is the construction of a surface outpost, exploratory drilling for finding sites with great water content is of paramount interest.

Another target of surface-based drilling is looking for potentially extant and extinct life on the Red Planet. To this end, the Perseverance rover, equipped with cutting-edge penetration instruments, landed on the Jezero Crater on Mars on 18 February 2021. During its current mission, the Perseverance drills the regolith underneath and collects and stores powdery samples in its chamber. The samples will be returned back to Earth in the future and they will be examined for the traces of any past or present tiny microbes and signatures through laboratory tests [35].

Furthermore, surface drilling plays an integral role in the efficiency and economy of programs such as mineral mining and water extraction [36]. Mineral exploitation is predominantly traced on the asteroids located in the Asteroid belt. They are considered as the limitless deposits of highly precious elements such as gold, platinum, nickel and iron. The exploitation of such minerals can partially or substantially satisfy the demands on Earth; hence, this would preserve the terrestrial environment from mining-derived footprints. Moreover, minerals such as iron can be deployed in in situ resource utilization programs, especially with the emerging technology of 3D printing. The on-site provision of aggregates can dramatically reduce the transportation of raw materials from Earth to the Moon or Mars. For comparison, the transportation cost of one kilogram of material from Earth to the Lower Earth Orbit (that is only $600 \mathrm{~km}$ distant from the Earth's surface) is USD 2000 per $\mathrm{kg}$.

So far, no underground excavation has been conducted within the lunar or Martian rocks. However, underground structures have been suggested by a number of investigators for the construction of subsurface outposts [37]. On the lunar and Martian surfaces, astronauts are susceptible to harsh environmental conditions such as cryogenic temperatures, dust storms, hazards of impact collisions, $\mathrm{CO}_{2}$ gas, etc. Moreover, the provision of essential materials and aggregates to build the surface outposts mentioned in the above paragraphs is highly demanding. The construction of such underground outposts can be carried out by the development of the naturally accessible caves or volcanic channels. In this case, the development of the initial cave or channel can be performed even by a simple handheld driller. The effect of the different parameters on the stability of the lunar/Martian underground structures can be evaluated through numerical modeling or mathematical algorithms, such as the Monte Carlo simulation [38,39].

As space geomechanics is closely intertwined with the future space colonization, a comprehensive review of present-day geomechanical advancements seems to be indispensable. In this research paper, a great attempt has been made to roughly cover all existing geomechanical aspects of and applications in space technologies. For this purpose, firstly, up-to-date lunar and Martian investigations on geological conditions and regolith characterization are described. Then, the construction of the surface outposts with a particular focus on the anchoring technique and landing/takeoff pads is discussed. In the subsequent section, the discussion revolves around the applications of surface drilling, including exploratory drilling, mineral mining and water extraction. Afterwards, the latest investigations on underground excavations for the construction of subsurface structures are recounted. Eventually, the paper concludes with a concise discussion on how the science of geomechanics can benefit space technologies to a greater extent. The structure of this 
paper is woven upon the belief that the current review provides a steppingstone for the further development of geomechanics applied to space technologies.

\section{Methods and Methodology}

The first part of this article elaborates the geological conditions of the Moon and Mars; without a description of prominently lunar and Martian geology, any study on space geomechanics manifests incomplete. Afterwards, the existing information about the physical and geotechnical properties of the lunar and Martian regolith is recounted. Moreover, morphological landforms together with the tectonic regimes are also described.

Beyond the Moon and Mars, geological investigations and sampling attempts have been made on other planets, such as Venus, or even on asteroids, such as Itokawa; however, those missions and results mostly failed or were limited to partial domains. Additionally, in some cases, the findings have not been declared yet.

\subsection{Geology of the Moon}

\subsubsection{Lunar Morphology}

Earth was formed nearly 4.5 billion years ago. Approximately at the same time, the evolution and accretion of the Moon occurred. Nevertheless, despite Earth, the lack of plate tectonics led to a rather simple traceable process of the lunar geological evolution [40]. The lunar landforms are either in the flat maria or highland regions. The maria represent the dark areas, while the highlands comprise the bright regions on the Moon. Both maria and highlands possess craters that have been formed by projectile impacts on the lunar surface.

Maria constitute roughly $17 \%$ of the lunar surface and are predominantly on the nearside hemisphere of the Moon. The elemental composition of the maria is analogous to the terrestrial dark basaltic rocks such as the lava erupted from the earthly volcanos or the basaltic formations beneath the oceans [41,42]. The highlands occupy nearly $83 \%$ of the lunar surface and are dominant in the farside hemisphere. They encompass feldspathic rocks described as Anorthosite. On Earth, Anorthosite rock is economically valuable for containing Titanium and is found in southern Scandinavia, Eastern Europe and northern America.

On the Moon, morphological features originate from four different mechanisms, including impacts (by macro- or micrometeorites), volcanic origins, tectonics and space weathering.

The smallest size of the craters can be in the order of micrometers, found in the reverted samples from the Moon to Earth. On the other hand, their diameter can reach $2500 \mathrm{~km}$ in some parts of the lunar surface [43]. Craters are further abundant in the highlands, since they were created in the very early ages of the Moon evolution and, consequently, underwent many more impacts.

The landforms with volcanic origins in the maria regions consist of wrinkle ridges, lava flows, domes, cones and sinuous rills [43]. Investigations have indicated that the nearside hemisphere contains a higher percentage of volcanic activities. The reason is that the volume of the heat-producing compounds in the Moon mantle is greater within this hemisphere compared to the farside one [44,45]. The wrinkle ridges are prevalent in the maria and might have also stemmed from the tectonics. The lava flows resemble tortuous channels which are averagely $100 \mathrm{~m}$ in depth, 1-300 km in length and 20-3000 m in breadth [46,47].

The lunar tectonic terrains are limited on the Moon and might have been created either by the volcanic activities or have meteorite-impact origins. The most widespread landforms include faults, wrinkle ridges and dikes. The collision of the large impactors with the lunar surface discharged a huge amount of kinetic and thermal energy on the surrounding rocks. This energy induced large cracks within the adjacent formations [48]. During the Apollo missions, some local moonquakes were recorded which have been considered as the source of the partial tectonic activities on the Moon surface $[49,50]$.

Erosion and space weathering have also left traces of their influences on the presentday morphology of the Moon. The lunar features have been continuously exposed to 
radiations, fluctuating temperatures and solar winds. This caused gradual degradation, erosion and filling of the surface with new weathered particles. In the subsequent section, the physical and geotechnical properties of such particles, called the lunar regolith, are described.

\subsubsection{Geotechnical Properties of the Lunar Regolith}

During the early ages of the Moon evolution, large meteorites collisions smashed the surficial rocks into separate fragments called "mega-regolith". In the final stages, small meteorites became dominant and crushed the upper surface of the mega-regolith to a finegrained powdery soil called "regolith". This incident intensely altered the physical and mechanical characteristics of the regolith compared to the original mega-regolith [51]. Due to the shortage of an atmosphere and magnetic field, the collision of the lunar surface with small-size particles occurs uninterruptedly [52]. Figure 1 demonstrates an idealized vertical profile of the lunar mega-regolith and regolith layers based on seismic investigations. The average depth of the lunar regolith is nearly $10 \mathrm{~m}$ while the average thickness of the underlying mega-regolith can amount to $25 \mathrm{~km}$ [43].

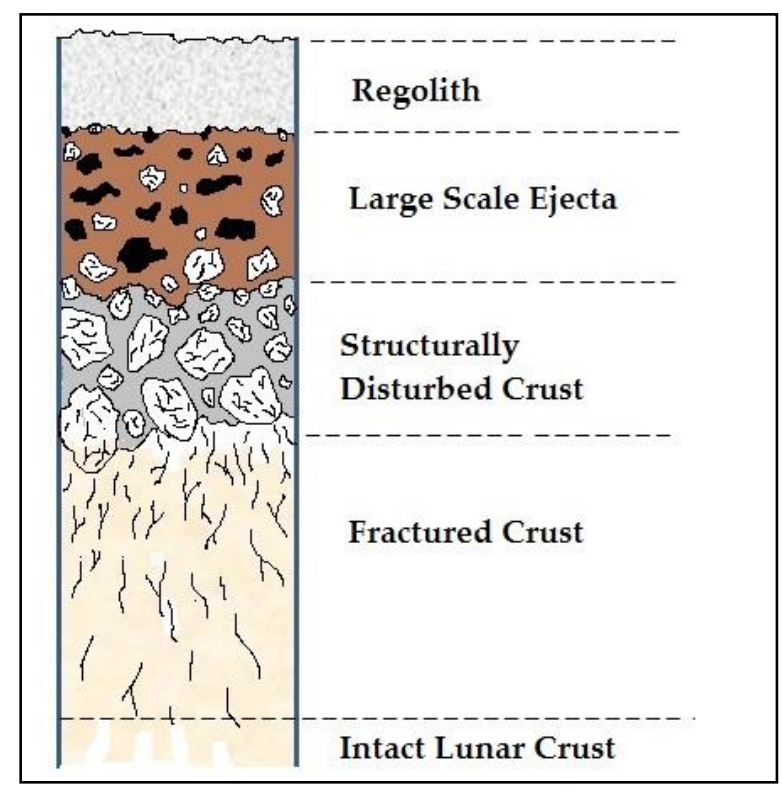

Figure 1. An idealized vertical profile of the lunar mega-regolith and regolith.

The physical and geotechnical characteristics of the lunar regolith were investigated during some sampling missions chiefly established by the Soviet and USA space agencies. The experiments were conducted either through on-board or terrestrial laboratories. Table 1 portrays a summary of the corresponding results representing the physical and geotechnical properties of the lunar regolith. The symbols of $C, \varphi$ and $\rho$ represent the values of cohesion, internal friction angle and bulk density, respectively. The properties of the lunar regolith vary between different sites and may even change with depth in certain locations [53]. However, since the lunar regolith was formed as a result of the previous impact processes, its mechanical response remains relatively identical in different spots on the Moon's surface. In contrast to the lunar regolith, terrestrial soils are more diverse in terms of physical and geotechnical properties. In general, the geotechnical nature of lunar or terrestrial soils depends on their mineralogy, grain size distribution and grain shape. In terms of mineralogy, the lunar regolith is more uniform than its terrestrial counterpart. The reason is that, on the Moon, the composition of the bedrock is less diverse than that of Earth's rocks; in other words, on the Moon, less than a hundred dissimilar minerals have been discovered, while, on Earth, more than several thousands of distinct rock minerals have been found [54]. 
Table 1. Physical and geotechnical characteristics of the lunar regolith.

\begin{tabular}{cccc}
\hline Mission & $\boldsymbol{C}(\mathbf{k P a})$ & $\boldsymbol{\varphi}\left(^{\circ}\right)$ & $\rho \mathbf{( g r / \mathbf { c m } ^ { 3 } )}$ \\
\hline Surveyor [55] & $0.15-15$ & 55 & - \\
\hline Luna 13 [1] & 0.0005 & 32 & 0.8 \\
\hline Lunar Orbiter [56] & 0.35 & 33 & - \\
\hline Surveyor 3 and 6 [57] & $0.35-0.70$ & $35-37$ & - \\
\hline Lunar Orbiter [58] & 0.1 & $10-30$ & - \\
\hline Lunar Orbiter [59] & 0.5 & $21-55$ & $1.54-1.75$ \\
\hline Apollo 11 [60] & $0.3-1.4$ & $35-45$ & $1.81-1.92$ \\
\hline Apollo 11 [61] & $0.8-2.1$ & $37-45$ & $1.80-1.84$ \\
\hline Apollo 12 [61] & $0.6-0.8$ & $38-44$ & $1.26-2.21$ \\
\hline Luna 16 [1] & $0.01-0.03$ & $29-35$ & $1.5-1.46$ \\
\hline Luna 20 [1] & 0.0015 & 26 & - \\
\hline Apollo 14 [62] & $<0.03-0.3$ & $35-45$ & 1.97 \\
\hline Apollo 15 [63] & - & 49.5 & \\
\hline
\end{tabular}

According to Table 1, the cohesion of the lunar regolith is averagely less than a few $\mathrm{kPa}$. On Earth, most soils have similar ranges of cohesion, except clay soils, which have higher values of cohesion. Moreover, the internal friction angle of the lunar regolith is averagely between $25^{\circ}$ and $45^{\circ}$, which is much more than that of terrestrial soils. The reason is that the lunar regolith has (granular) sharper grains because of the meteorite bombardments. Sharper grains form a more resistant structure against outer shear stress. Based on Mohr-Coulomb failure criterion, the shear strength of a soil/rock sample is equal to the summation of the cohesion force and frictional force between the grains [53]. The general form of this criterion is

$$
\tau=C+\mu \sigma_{n}
$$

where $\tau$ represents the shear strength of the sample (Pa), $C$ indicates the cohesion (Pa), $\mu$ is the dimensionless coefficient of internal friction and $\sigma_{n}$ represents the normal stress on the failure plane (Pa) [53]. Shear failure does not occur on any plane for which the shear strength is larger than the shear stress. The coefficient of internal friction is obtained through the following relationship:

$$
\mu=\tan \varphi
$$

where $\varphi$ represents the internal friction angle [53].

In regard to density, the density of lunar and terrestrial soils falls approximately in an identical range. Common soils and sedimentary rocks on Earth have a density value between $1.5 \mathrm{gr} / \mathrm{cm}^{3}$ and $2.2 \mathrm{gr} / \mathrm{cm}^{3}$.

\subsection{Geology of Mars}

\subsubsection{Martian Morphology}

The most obvious geological attribute of Mars is the conspicuous dichotomy between the northern and southern hemispheres [64]. In the northern hemisphere, the low-lying plains with the trivial impact craters are apparently dominant. Oppositely, the main topographical landforms in the southern part include highlands with enormous signatures of the impact craters (Figure 2). Similar to the Moon, the lack of plate tectonics brought about the preservation of the volcanic records occurred in Mars' history [65]. The second striking attribute of Mars is the notable variation of the crustal thickness in the northern and southern hemispheres [66,67]. To explain this particular morphology, the Martian dichotomy has been ascribed to the distinction between the impact craters' density in the 
northern and southern hemispheres as well as the evident discrepancy in crustal thickness of those hemispheres. On the Martian surface, there are also Earth-like channels indicating water streams that existed during the planet evolution [68,69].

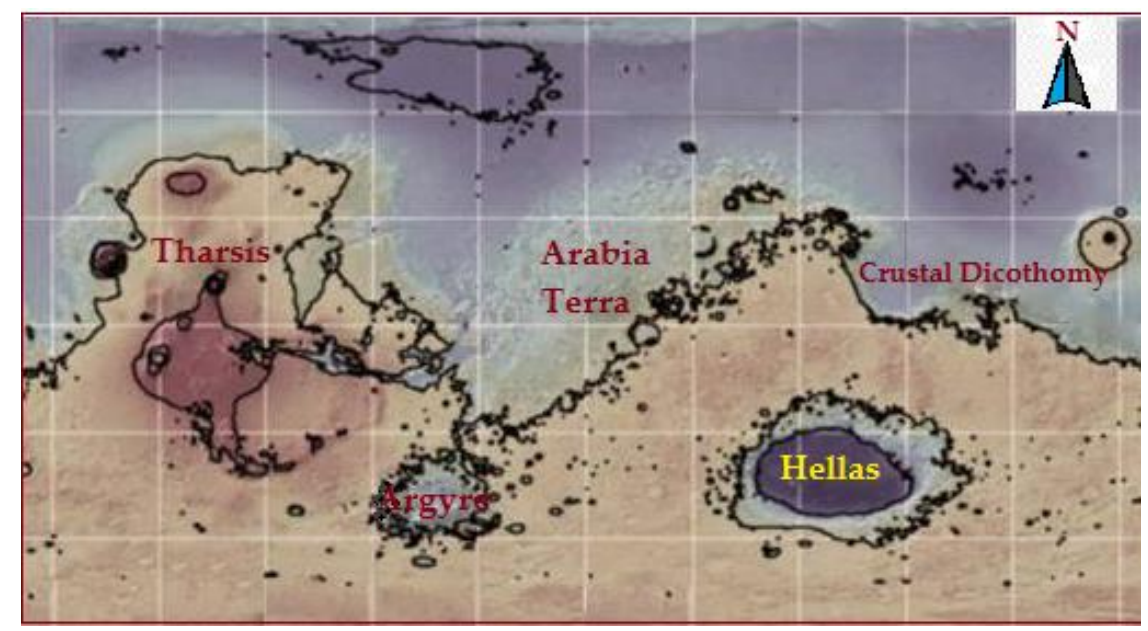

Figure 2. Morphological dichotomy on Mars.

The diameter of Mars is approximately half of the terrestrial diameter and two times the diameter of the Moon. Moreover, Mars' gravity is $3.71 \mathrm{~m} / \mathrm{s}^{2}$. The crustal composition is dominantly basaltic with a moderate thickness in the range of $5-100 \mathrm{~km}$. There is no magnetic field nor plate tectonics on the Red Neighbor [70,71]. On Mars, there is a thin atmosphere containing roughly $95 \% \mathrm{CO}_{2}, 3 \%$ Nitrogen, 1.6\% Argon and, slightly, water and Oxygen.

Similar to the Moon, phenomena such as meteorite impacts, volcanism, tectonics and erosion were the major agents in the evolution of the Martian surface. The large Hellas Planitia region in the southern hemisphere is an illustration of the impact craters on Mars. The deepest point on Mars lies in this region [72]. Two common types of volcanic features on Mars are shield volcanoes and highland Pateraes [73]. Tharsis province, located in the western part of the Red Planet, is a highland area with volcanic origin [74]. Mars has a whole raft of tectonic structures, including compressional structures (e.g., wrinkle ridges) and extensional ones (e.g., extensional faults). Erosional landforms generated by fluids, probably water, are situated in the low-altitude crustal dichotomy boundary [75].

\subsubsection{Geotechnical Properties of the Martian Regolith}

A wealth of geological and geotechnical information has been acquired by the Viking 1 and Viking 2 landers, Sojourner rover (part of the Pathfinder mission), Mars Global Surveyor (MGS), Mars Odyssey spacecraft, Mars Express spacecraft, Spirit rover, Opportunity rover, Mars Reconnaissance Orbiter (MRO), Phoenix lander, Curiosity rover, InSight rover and Perseverance rover [76]. Table 2 demonstrates the measured physical and geotechnical data of the Martian regolith. According to this table, the cohesion of the Martian samples is averagely in the range of a few $\mathrm{kPa}$. Hence, it can be said that their cohesion is close to the lunar and terrestrial soils, except clay. In contrast to the lunar regolith, the angularity of particles within the Martian regolith is small. Thus, the average internal friction angle of the Martian regolith is relatively less than that of the lunar one. On the other hand, both the lunar and the Martian regolith possess higher values of internal friction angle than that of common Earth soils. Furthermore, the density of the lunar and Martian regolith falls within the normal range of terrestrial soils.

The Viking 1 and Viking 2 landers took powdery samples with their special scoop flown on the mechanical arms. The Sojourner rover used several approaches, such as the wheel trenching technique, to monitor the electrical current and capture high-quality photographs of the dug pit to calculate the geotechnical properties of the regolith [77]. 
Currently, in October 2021, the InSight rover is acquiring geotechnical data of the Martian regolith through a mobile penetrometer (Mole) which was designed to penetrate into the subsurface rock up to the depth of $5 \mathrm{~m}$ [78]. The ultimate geotechnical information acquired by the InSight rover has not been declared yet. Another active rover is Perseverance, which will send the data back to Earth probably between the years of 2026 and 2030.

Table 2. Physical and geotechnical characteristics of the Martian regolith.

\begin{tabular}{cccc}
\hline Mission & $\boldsymbol{C} \mathbf{( k P a )}$ & $\boldsymbol{\varphi}\left(^{\circ}\right)$ & $\rho\left(\mathbf{g r} / \mathbf{c m}^{\mathbf{3}}\right)$ \\
\hline Viking 1 [79] & $1.6 \pm 1.2$ & $18 \pm 2.4$ & $1.15 \pm 0.15$ \\
\hline Viking 1 [79] & $5.1 \pm 2.7$ & $30.8 \pm 2.4$ & $1.60 \pm 0.4$ \\
\hline Viking 1 and Viking 2 [79] & $1-10$ & $40-60$ & 2.6 \\
\hline Viking 2 [79] & $1.10 \pm 0.80$ & $34.5 \pm 4.7$ & $1.4 \pm 0.2$ \\
\hline Sojourner [80] & $0.34 \pm 0.57$ & $31.4-42.2$ & $2-2.2$ \\
\hline Sojourner [80] & $0.18 \pm 0.53$ & $15.1-33.1$ & $1.07-1.27$ \\
\hline InSight [81] & $1-2$ & pending & pending \\
\hline
\end{tabular}

\subsection{Space Outposts}

\subsubsection{Anchoring Technique}

To stabilize the future surficial outposts and structures on planetary bodies, the versatility of anchors seems strikingly tempting and evitable. Numerous investigations have been carried out to evaluate the anchoring usability for the stabilization of lunar and Martian surface bases [17-20]. Anchors can also provide a much safer condition for rovers and astronauts during missions involving challenging, dangerous media such as cliffs, low-lying craters, loose sand, icy regolith, dusty condition, etc. The microgravity issue is dominant around asteroids and comets. Hence, for sample acquisition or mineral mining, this technique can be substantially potent. An intriguing configuration of such anchoring technique can be found in [82]. The success of any inclined drilling is also dependent on the angle between the direction of the drilling (anchor) and strike of the joint sets within the subsurface rocks [83].

\subsubsection{Landing/Takeoff Pads}

One of the chief challenges of space missions is the landing of the spacecrafts on the planetary surfaces. From the early generations of spacecrafts to the state-of-the-art space rovers, the landing manners have been continuously modified. A new idea to improve landing operations is the application of in situ regolith for the construction of rigid and stable landing pads. Such pads curtail the dust issues both during landing and takeoff. Even during takeoff, an energetic plume is released by the engines of the spacecraft, resulting in the generation of artificial ditches or pits on the base regolith, or even in collisions due to rocks-spacecraft interactions [84]. An interesting manner for the construction of such landing pads can be found in [85].

\subsection{Planetary Drilling Mechanisms}

On the one hand, the main challenges in the design of planetary drillers include the following: (a) Mass limitation; for instance, for drilling up to depths of $2 \mathrm{~m}$, the maximum weight of the driller (including the main rover and drill instruments) has to be between 10 and $20 \mathrm{~kg}$. (b) Power constraints; the power of the prevalent drilling tools falls generally in the range 10-20 W. (c) Drilling fluid problem; i.e., owing to the low pressure and temperature, fluid cannot be used for cuttings' removal. On the other hand, while drilling, additional issues may be encountered; for instance, the initial interaction between the bit and the regolith's surface is almost commonly accompanied by the vibration and positioning error of the bit, thereby leading to the borehole deviation from the main 
trajectory. Furthermore, the heat transferred from the bit-regolith interface can disperse some volatiles, such as water molecules.

The prime applications of the drilling techniques on planetary objects encompass sample acquisition (powdered or cores), water extraction, mineral mining and anchoring. The latter is described in the previous section. For all mentioned applications, the drilling operation creates a "cut volume" in the top regolith or subsurface rocks, hence taking samples, measuring the water content, or determining the grade of a precious mineral in the dug hole.

Different drilling mechanisms capable of sampling (powered or core) acquisition have opened various fronts for mankind's future space colonization. So far, several types of drilling mechanisms, such as mechanical, thermal, optical and ultrasonic drilling techniques, have been developed by various investigators and designers. However, further improvements and enhancements of their mechanisms are much needed. In this section, the major conceptualized drilling mechanisms for planetary sampling/coring are elaborated.

\subsubsection{Surface-Preparation Tools}

The rocks on the lunar and Martian surfaces are chemically and physically weathered by environmental agents such as solar winds, radiations, dusts, etc. Sometimes, the purpose of the space mission lies in surface inspection, such as taking pictures from the fresh surface of the rock. In this case, the covering dust is removed from the rock surface by surface-preparation tools. Such tools involve grinders, the rock abrasion tool (RAT) and brushes, which provide a freshly flat area for subsequent measurements. An example of this application is the RAT used on the InSight and Opportunity rovers sent to Mars [86]. It also contained grinders and brushes. The RAT could efficiently abrade the rock and created a cylindrical hole with $4.5 \mathrm{~cm}$ in diameter and $5 \mathrm{~mm}$ in depth within the altered top layer [87].

Another example is the grinder mounted on the Beagle 2 rover launched in December 2003 by ESA part of the Mars Express mission. The rover was designed to look for the signs of any potential past life in the shallow Martian rocks. Its grinder could create a smooth area for X-ray (for age dating) and Mossbauer spectrometers (for composition determination) in the upper rock surface. Unfortunately, the rover could not contact with Earth after landing on Mars. Despite great efforts, no signals were received from the rover. In February 2004, the ESA announced that the mission was lost. In 2015, NASA's Mars Reconnaissance Orbiter found the Beagle 2 rover on the Martian surface. From the photographs taken, it was inferred that the antenna of the rover could not operate because the two solar panels of the rover had not successfully opened.

\subsubsection{Scoops}

Scoops are very simple buckets that can pick up a small volume of unconsolidated regolith, handle it, then transfer it into the special chambers emplaced on the rover for on-board measurements or future terrestrial laboratory trials. Simplicity is their main advantage; nevertheless, they are inefficient in trenching highly packed/icy regolith.

In 1967, the manned landers of Surveyor 3 and 7 were equipped with a scoop that could lift $100 \mathrm{~cm}^{3}$ of the lunar regolith up to the depth of $30.6 \mathrm{~cm}$. The length and the breadth of the bucket were 12 and $5 \mathrm{~cm}$, respectively. Moreover, Surveyor 7 could estimate the physical properties of the trenched regolith through the analysis of the motor current data.

Between 1975 and 1982, Viking 1 and Viking 2 were the first landers that could sample the Martian regolith [88]. Their collector (bucket) was able to trench the Martian regolith and deliver the sample to the on-board laboratory for subsequent chemical and biological measurements. Similar to the Surveyor 7 lander, the physical properties of the Martian regolith were calculated using the motor current and wheel position.

In May 2008, searching for water, the Phoenix lander landed on the Martian northern pole. It was kitted out by an integrated assembly of a scoop and a micro-driller tool for trenching the compacted permafrost [89]. The whole assembly was called Rapid Active 
Sampling Package (RASP). The scoop was a container flown on the robotic arm. Within the scoop, a micro-drill was installed to drill the regolith beneath the scoop container. The cuttings were handled into the container through a slot in the lower part of the container [90].

\subsubsection{Moles}

Moles are mobile penetrometers that can propel themselves into the poorly grained regolith or unconsolidated soils. This mechanism was deployed firstly in the Luna programs, such as the Lunokhod 1 rover mission [91]. Within the mole, there was a hammering mechanism that penetrated into the loose regolith and even permafrost. The initial Russian layout was $1 \mathrm{~m}$ in length and $10 \mathrm{~cm}$ in diameter.

The ESA slimmed down the initial Russian prototype to a miniature mole with $0.33 \mathrm{~m}$ in length and $2 \mathrm{~cm}$ in diameter. According to laboratory tests, this reduced-size mole had the capability to pierce through the lunar/Martian regolith up to the depth of $5 \mathrm{~m}$. The main advantage of the moles is their small need of energy or power. Furthermore, the ESA developed an instrumented mole system which was capable of carrying scientific sensors into the hole. An example for such applicable sensors is a potential thermocouple for recording the temperature of the drill bit versus the drilling time or depth. The instrumented mole system included two separate moles (penetrating mole and sensor-carrying mole) that were connected through a wire.

\subsubsection{Ultrasonic Drills}

Ultrasonic drill systems incorporate high-frequency oscillations with a normal drill. With this method, low-amplitude oscillations are turned into high-amplitude ones, transferring energy to the bit through a special transducer within the tool. Thus, the basis of the ultrasonic drill systems is fracturing the rock by continuously sending the dynamic impulses to the rock-bit interface [92,93]. Drills equipped with an ultrasonic mechanism had already been deployed in the drilling of metals [94,95]. Maurer remarked that the ultrasonic drilling (USD) is vastly productive, especially when the bit is not full faced [96]. In the case of coring bits, the drilling efficiency intensely amplifies, as the bit is not forced to break and crush all the bit-rock interface area.

During the two most recent decades, a great deal of attempts has been made to develop the USD mechanism for future space programs. Barcohen et al. fabricated an Ultrasonic Driller/Corer (USDC) for NASA's space missions seeking past life on planetary bodies [97]. The USDC was a lightweight drill capable of capturing both powdery and core samples, as well as carrying sensors into the hole. On a more positive note, the USDC needed a low amount of energy to drill the icy rocks or highly compacted regolith under microgravity conditions. The USDC has been improved in different ways so far $[98,99]$. For instance, $[100,101]$ used the sampling-purpose bits containing internal cavities in their structures to drive the crushed particles towards the inner part of the drill string.

Cuttings' removal is a highly troublesome issue wherever drilling fluid may not be applied. Poor bottom-hole cleaning shrinks drilling efficiency remarkably. In an attempt, Badescu et al. manufactured a drill bit with outer spiral flutes acting as an auger drill for the transmission of the cuttings from the bottom hole towards the surface [102]. This strategy could partially meet the requirement for compressed gas as the drilling fluid. Bar-Cohen et al. designed an all-in-one coring bit that entailed a wedge for separating the core from the rock medium, a set of internal springs for holding the core and a push rod for pulling out the core [103]. Further developments made the depth reachable to $1 \mathrm{~m}$ via the all-in-one bit. The ESA also carried out a number of investigations on the application of USD systems in space missions [104]. 


\subsubsection{Conventional Drilling}

Amongst the Earth-based drilling techniques, conventional rotary-percussive drilling maintains the highest efficiency; however, the mass budget restricts the application of heavy mechanical rigs for extraterrestrial targets.

The process of extraterrestrial drilling operations can be divided into two main stages. The first stage is rock fragmentation, which plays a key role in the whole drilling efficiency. After the fragmentation stage, the rock cuttings must be removed from the borehole (cuttings' removal) by a gas or a fluid. Figure 3 demonstrates the three major types of conventional drilling: auger drilling, coring drilling, and pneumatic drilling.

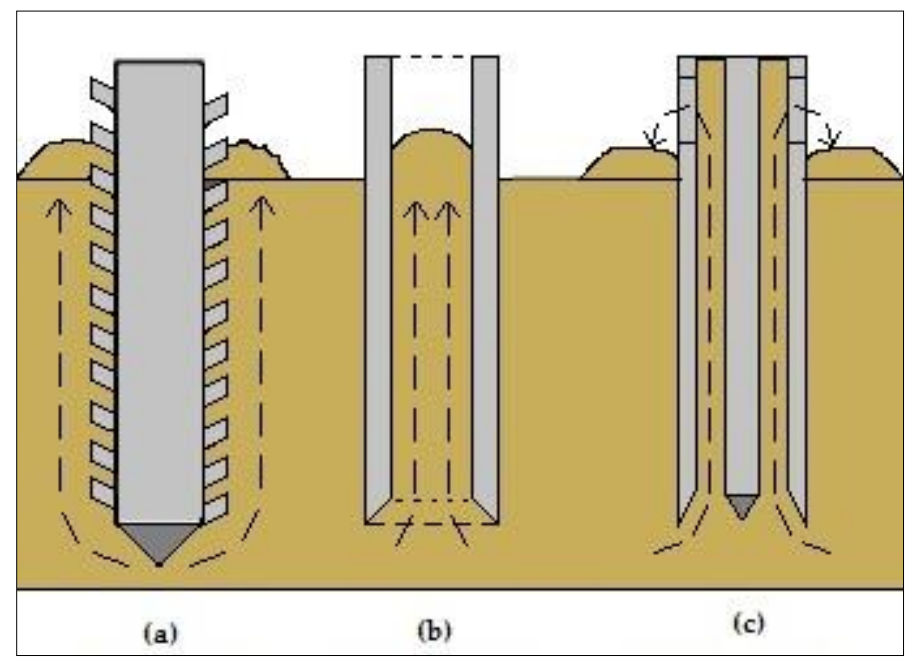

Figure 3. Common types of conventional drilling: (a) auger drilling; (b) coring drilling; (c) pneumatic drilling.

The first mechanism in Figure 3a, the most common planetary conventional drilling, is auger drilling, which involves a screw-shaped penetrator facilitating bottom-hole cleaning. With this method, drilling fluids cannot be used to move up the cuttings, as the cryogenic-temperature and low-pressure conditions freeze or evaporate the fluid. Therefore, with auger drilling, the rate of penetration steadily diminishes as the drilling operation proceeds to further depths. Auger drilling is suitable for dry, loose regolith. The most well-known space agencies, such as ESA and NASA, have used the auger mechanism in their drilling programs.

The middle mechanism in Figure $3 \mathrm{~b}$ is employed for coring operations when taking the intact cores is preferred collecting powdered samples. From the viewpoint of scientific value, cores offer many more data than powdered specimens. For instance, the stratigraphy within the hole is preserved through the taken cores and, additionally, some volatiles can be retained in the central parts of the samples. Many of the previous robotic rovers were not capable of capturing core samples; however, the novel technology has benefited rovers such as Perseverance, which can take and store cylindrical coring samples within special on-board chambers.

The third layout in Figure $3 c$ is pneumatic drilling, proposed by [105]. They found that a compressed gas (as drilling fluid) can efficiently remove an amount of 6000-9000 kg of debris from the bottom hole in lunar regolith medium. On Mars, a gas such as $\mathrm{CO}_{2}$ can be taken from the atmosphere even if it is tenuous [106]; however, on the Moon, the gas must be considered in the mass budget to be taken from Earth. If the ambient pressure is lesser than the triple point of the water, the drilling fluid can be in the form of water-ice sublimation. 


\subsubsection{Challenges of Extraterrestrial Drilling}

Extraterrestrial drilling operations encounter two serious types of challenges, environmental and technical ones [107]. Environmental challenges stem from the difference between the physics of planetary bodies and that of Earth. The first environmental challenge is the lack of atmosphere on the Moon and Mars. Because of this problem, it is not feasible to use drilling fluid (mud) while drilling. The drilling fluid performs crucial tasks such as bit cooling, cuttings' removal, borehole stability, etc. Currently, the problems related to the utilization of drilling fluid on planetary bodies are considered as the most formidable obstacle for extraterrestrial drilling operations. The second environmental issue is microgravity; this problem brings about the instability of drilling machines during their operations. Furthermore, drilling machines must have more weight to impose adequate forces on the bit. The third environmental issue is temperature; in the lunar and Martian polar areas, the temperature averagely fluctuates around $-230^{\circ} \mathrm{C}$ and $-140{ }^{\circ} \mathrm{C}$, respectively [88]. Thermal stresses derived from this very low range of temperature impairs the different organs of drilling machines. Furthermore, temperature is another obstacle prohibiting the usage of fluids during drilling operations. The fourth environmental issue is the abrasiveness of lunar and Martian regolith; the abrasive, sharp particles of the lunar and Martian regolith can penetrate into the working parts of the drilling machine and gradually impair them. Moreover, drilling through such abrasive material accelerates the bit's wear [107].

On the other side, technological challenges are intensely dependent on the status of technology and versatility of more potent instruments in drilling operations. The first technological challenge is expensive transportation; this matter puts pressure on space agencies to design smaller and lighter drilling machines which cannot successfully drill in the problematic conditions of planetary bodies. The second technological challenge is the impossibility of the utilization of steel casings for the prevention of borehole instability. Such steel casings are too heavy and bulky for transportation between the Earth's and lunar/Martian surfaces [108]. The third technological challenge is the limitation of the drilling power. As no liquid fuel can be used on the Moon and Mars, other limited sources such as electric or solar batteries are utilized to provide the essential power for the drilling machine. In contrast to the fossil fuels on Earth, such electrical and solar sources produce much less power for drilling operations.

A wide range of initiative drilling machines has been designed and manufactured for off-Earth drilling by different space agencies throughout the world. Some examples are here elaborated. In 2005, one the most applicable drilling machines, called Mars Astrobiology Research and Technology Experiment (MARTE), was designed during a partnership between NASA, Honeybee Robotics and Centro de Astrobiologia [109]. MARTE was a rotary coring machine which was able to efficiently take core samples from depths up to $1 \mathrm{~m}$. Furthermore, it was capable of adding extra drilling strings for penetration into the lower depths. The maximum reachable depth was $10 \mathrm{~m}$. The second potent drilling machine was Drilling Automation for Mars Exploration (DAME). In contrast to MARTE, the DAME machine possessed more mobility, while they were similar in terms of dimensions and power consumption. Moreover, DAME was equipped with a set of below- and above-ground sensors to recognize and tackle possible drilling issues [109]. A third powerful drilling machine was called Subsurface Planetary Exploration Core Extracting System (SPECES) [110]. It was manufactured to perform an efficient mechanism of dry cuttings' removal as well as preservation of borehole stability. With this machine, dry cuttings' removal was found to be successful and efficient. In addition, some enhancements were applied to prevent clogging issues at the regolith-bit interface. Additionally, some particular coring bits with thinner walls were utilized to reduce energy consumption. Those enhancements dramatically decreased the drilling time as well as the borehole instability [110]. 


\subsection{Water Extraxtion}

Water extraction is another important application of surface drilling. Recent investigations have proven the existence of icy regolith at the Moon's and Mars' poles [36]. Presently, the most demanding material that space agencies, chiefly NASA and European Space Agency (ESA), are looking for is water. In the polar lunar regions, the rock is in the form of regolith with frozen ice and the water content amounts to $6 \%(5 \% \pm 2 \%)$. Water can be used directly for astronauts' consumption. In addition, it can be decomposed to Hydrogen and Oxygen that may be utilized as an on-space fuel for spaceflights.

On Earth, the drilling of water wells, together with geo-electrical methods, is utilized to discover underground water resources [111]. Many drills are being designed to seek water in the polar regions of the Moon and Mars. Such drillers are equipped with waterdetection tools such as neutron probes. The uniaxial compressive strength (UCS) of frozen regolith depends on ambient temperature, grain size and water content. As the temperature of the frozen regolith decreases, the value of the UCS increases. The average grain size of the lunar regolith falls in the range of silts (between clay and sand). As the particle size increases, the values of the UCS of the regolith intensifies. Moreover, the UCS of frozen soils is a function of water content $[84,112]$. The UCS of dry soil is always less than the frozen soil-water admixture. If the frozen soil is saturated, the UCS drastically soars and amounts to the maximum extent. However, a further rise in the water content cuts down the UCS until it reaches the UCS of pure ice [86].

As the regolith is frozen in the polar regions, its mechanical behavior approaches that of common terrestrial rocks. The parameter of UCS is a good indicator of mechanical response of the different materials to the drilling operations. In a research study, a number of laboratory experiments was carried out to study the effect of freezing on the mechanical properties of silt soil [113]. The grain size of the lunar regolith is in the range of silt grains; they found that, as the temperature decreased from $0{ }^{\circ} \mathrm{C}$ to $-120^{\circ} \mathrm{C}$, the UCS of the silt samples increased from $7 \mathrm{MPa}$ to $70 \mathrm{MPa}$. However, for lower temperature values between $-120{ }^{\circ} \mathrm{C}$ and $-200^{\circ} \mathrm{C}$, a reduction equal to $10 \mathrm{MPa}$ was observed in the UCS. Hence, at $-200{ }^{\circ} \mathrm{C}$, the UCS value of the silt samples was nearly equal to $60 \mathrm{MPa}$. Many terrestrial rocks such as sandstones have a value of UCS close to $60 \mathrm{MPa}$. They also studied the variation in the UCS of pure ice with temperature. The UCS of pure ice at $-120^{\circ} \mathrm{C}$ and $-200{ }^{\circ} \mathrm{C}$ was recorded as $14 \mathrm{MPa}$ and $21 \mathrm{MPa}$, respectively. It is worth mentioning that some high-porosity sandstones have an equal UCS value [113]. Thus, it can be seen that the UCS of frozen soils is close to that of rocks such as weak or resistant sandstones.

Temperature fluctuations impose cyclic thermal stresses on the ice-regolith admixture, thereby leading to a dramatic change in its mechanical properties [114]. From the lunar surface to the depth of $60 \mathrm{~cm}$, the average porosity of the regolith is approximately equal to $43 \%$. The average density of the lunar regolith lies in the range of $0.92-3.1 \mathrm{gr} / \mathrm{cm}^{3}$. Hence, the mass of water in the regolith is calculated to be around 19\%. The new space missions have found that the water mass in the polar lunar regolith is more than $10 \%$.

During drilling operations, the least possible heat must be produced between the drill bit and the lunar regolith, because, in the vacuum medium, the frozen icy water immediately turns to vapor (volatile material); thus, the water recovery (the volume of water per drilling length) drastically reduces. Consequently, the revolutions per minute (RPM) must be controlled to reduce the generated heat and friction.

\subsection{Mining}

Space mining on planetary objects pursues two main targets-the first is the exploitation of precious materials such as rare elements and the second is providing the long-term space colonization with in situ resource utilization. The former is highly efficient in the reduction in mining environmental impacts on Earth, while the latter dramatically reduces the expenditures of aggregate transport to the lunar/Martian surface. The different planetary conditions almost entirely affect all the aspects of feasible mining projects in space. 
For further investigations on the Moon's and Mars' surfaces, providing Oxygen and Hydrogen is imperative as a propellant for future spaceflights. Beyond Oxygen, Hydrogen and water, other invaluable minerals such as Helium-3 and platinum are tracked for mineral mining purposes on the Moon's surface, asteroids and comets. An economic evaluation of non-terrestrial mineral mining can be found in [115]. Mineral mining on asteroids or comets is carried out by cutting-edge robots deploying mechanical, thermal and optical drilling operations. The microgravity conditions around asteroids and comets impose prohibitive limitations on the robots' stability during the drilling and collecting of mineral samples. The anchoring technique has been proposed for providing robots with stability on such celestial bodies.

On the other hand, humanity has already commenced the colonization of planets such as the Moon and Mars. The environment of Mars is better for future human civilization as it has more gravitational acceleration, less temperature fluctuation, higher pressure and thicker atmosphere than the Moon [116]. The design of the reliable machinery for extraterrestrial mining needs much more stringent standards than Earth-based equipment. Such machinery must be manufactured from highly durable materials sustaining the harsh lunar/Martian environments. Other essential criteria for mining machinery include minimal maintenance as well as potent versatility for digging, loading and hauling tasks. Podnieks et al. investigated the environmentally viable mining machinery on the Moon's surface [117]. He discovered that two sorts of mining machinery are superior to be designed and fabricated. The first machine must be capable of loading the fragmented rock while the second one hauls the materials toward the destination (dump).

Another issue that mining machinery encounters is the Martian or lunar dust covering of the possible camera and electronic gadgets. On Earth, the micro-scale dust derived from mining activities enters the engine of the machinery, thereby causing prevalent premature jams or breakdowns. During mining operations on the lunar and Martian surfaces, there is no or weak atmosphere. Hence, the mining-derived dust propagates in space and travels a long path with high speed [118]. Such issue must be taken into consideration in the design phase of mining equipment. Tele-operation and automation are inseparable from tough space mining.

\subsection{Underground Excavations}

The excavation of underground structures can be executed for the construction of subsurface outposts, or even in underground mining. The latter seems remarkably avoidable, as non-terrestrial surface mining has not been developed yet. However, if the future space colonization tends to use underground outposts, underground mining will appear reasonably cost-effective and applicable. The innovative usage of aggregates in engineering applications cuts down the final expenses of projects markedly [119-121]. In this case, underground mining provides an unlimited in situ resource for the construction of the potential outposts.

Underground outposts can be built by using miniature tunnel-boring machines (TBMs). On Earth, a broad enhancement has been obtained in the TBMs' manufacturing and performance. The TBMs' prime scope is to create an equilibrium between rock pressure and the inner pressure of the machine. The major benefits of the TBMs are: (a) automatic insertion of pre-cast linings during the excavation process, (b) fast advancement rate and (c) symmetric and regular profile of the outpost. Some numerical simulations have indicated that the tunnels excavated by TBMs under the surface of Mars are safe and stable [37]. It was inferred that the lack of pore pressure, together with the presence of microgravity conditions, assures the natural stability of the tunnels. According to the poroelasticity theory, the presence of pore pressure dramatically reduces the strength of porous soils and rocks $[122,123]$.

On a negative note, the existing TBM technology cannot meet the demands and expectations of space drilling. Currently, the main challenge of TBM utilization is that there is no atmosphere pressure on the machine cutter-head, while the existing TBMs operate 
on the basis of the creation of the balance between the formation pressure and the inner pressure of the machine. Some companies are investing on the development of miniature TBMs to function successfully in future space programs.

Furthermore, underground excavations can be implemented through the blasting with chemical explosives. Such explosives were adopted in the seismic surveys in the Apollo lunar programs. Based on dozens of research projects, some chemical explosives have been proposed for blasting in vacuum conditions. The mathematical equations for blasting operations in vacuum and microgravity conditions were derived by [124].

\section{Discussion}

Compiling all the important aspects of space geomechanics in an integrated framework was the motive for drafting this research paper. The large extent of such aspects clarifies the importance of the science of geomechanics in the contemporary and nearfuture space exploration. Two centuries of field experiences have allowed engineers and designers to manufacture tools that operate compatibly with the physics of Earth. Different planetary physics, including microgravity, vacuum conditions, lack of atmosphere and planet-dependent temperature and pressure, prevents the utilization of Earth-based equipment on other celestial bodies. Therefore, to develop tools capable of operating on distant planets, there is an essential need to develop more on-Earth laboratories in which the principles of other planetary physics govern. The subsequent step will be the instrumentation and fabrication of tools adaptable to other planetary conditions.

During the two most recent decades, geomechanical investigations, especially on Mars, have been more expedited than those on other planets, such as the Moon or Venus. As Mars seems a promising second habitable planet for mankind, more geomechanical investigations are needed for further discoveries. The establishment of surficial or subsurface outposts on Mars will marvelously lead to acquiring further information about the challenges of different governing physics on extraterrestrial planets.

Conceivable in situ resource utilization is a sophisticated idea in space mining. On Earth, new technologies such as tele-operation mining must be further developed to contribute to future mining activities on other planets such as Mars. Unmanned operations and automation must be undertaken with the possible simplicity but adequate flexibility to reduce the risk of any stoppage or suspension during the mining process. In all mining projects, sufficient, on-time maintenance is inevitable seminal work. This must be programmed with the minimum need of human intervention. Furthermore, potential requirements such as welding in vacuum conditions must be also considered.

During mining operations, the equipment exerts shear forces on the regolith to cut it from the lunar/Martian surface; the stability of such equipment through the anchoring technique can be probed and studied. To help the mining machines operating on Martian rocks, supplementary blasting, especially with the novel plasma blasting technique instead of the use of chemical explosives, might be adoptable. The application of a belt conveyor assisted by the natural gravity force can be assessed as an alternative for the haulage machines.

Continuous redesign and improvement of drilling tools, such as bits, rods, power systems and cuttings' removal systems, must be performed to identify new solutions for possibly pressing issues. The drilling of basaltic rocks on the Moon's and Mars' surfaces requires a high amount of energy to be performed. Hence, energy optimization must be the main criterion in the design of planetary-targeted drill tools. While testing drill tools in terrestrial simulants, the presence of potential basaltic boulders with more strength than the surrounding regolith must be considered. While most of the space drilling machines have focused on the penetration into the lunar and Martian icy regolith, adequate development of drilling equipment for high-temperature conditions, such as those on Venus, must not be overlooked.

Bottom-hole cleaning is the main problem in reaching the farthest subsurface depths. The utilization of compressed gas as drilling fluid is imperative to be further investigated. 
Cooling the bit is another advantage of the utilization of compressed gas in a drilling system. On Mars, the pressure of the atmosphere is very low; consequently, there is no need to supply a great amount of gas to be compressed as drilling fluid in the pneumatic technique [105]. A new, innovative method for the evaluation of volatile content in an arbitrary soil has been developed in 2020 [125]. With this technique, a gas analyzer for the evaluation of the percentage of different gases within the soil is emplaced in the ground. The novel software, together with the potent hardware, provides data in a short time with high accuracy. Such methods can be deployed for the measurement of the gas content within the lunar and Martian regolith. Hence, not only the gases from the atmosphere can be employed as the compressed gas, but also the gas content within the regolith can be evaluated for this purpose.

In contrast to continuous coring, selective coring is much more reasonable and economical. Continuous drilling requires the frequent removing of cores from the core barrel, thereby leading to potential delays in the drilling process. Core capturing is also a problematic issue in planetary drilling. A reliable system for core capturing and handling appears to be quite crucial. A disastrous scenario for any drilling operation happens when the bit or drill string is stuck. This situation becomes extremely complex if the lunar or Martian regolith freezes. Drastic plans must be devised to retrieve the lost bit/drill string from the hole. This necessitates both dynamic software platforms and reliable hardware instrumentation.

\section{Conclusions}

This paper covers the main aspects of geomechanics in past and present extraterrestrial applications. It commences with the description of the up-to-date geological and morphological features of the Moon and Mars. Then, the physical and mechanical properties of both lunar and Martian soils are described and tabulated. In the next step, the most prominent geomechanics aspects of anchoring, drilling, water extraction, mineral mining and underground excavations are portrayed.

Drilling is deemed as the most versatile branch of space geomechanics for all applications, including water extraction, mineral mining, anchoring and underground excavations. Although there has been a great deal of advancements in this field, further developments must be considered in the design and manufacturing of low-mass and low-power drilling instruments. For drilling operations, the pressing problem is the impossibility of usage of drilling fluids to cool the bit and to remove the cuttings from the bottom hole. This problem intensely decreases the drilling efficiency and, reversely, increases the time and costs of the operations. Expansive investigations on fluids compatible with the harsh environmental conditions of the Moon and Mars are much needed. Furthermore, the majority of drilling instrumens have been fabricated for low-temperature environments such as that of the Moon and Mars. However, for other planets such as Venus, a comprehensive plan must be devised for crafting the drills adaptable to extremely hot conditions.

Further investigations are essential in terms of in situ resource utilization. The lunar and Martian regoliths contain minerals which can be used as raw materials in the construction of outposts, fuel generation, production of drilling fluids, etc. Novel approaches are imperative to contribute to measuring the mineral composition and volatile content of the lunar and Martian regolith through faster and more efficient manners.

Since a large proportion of current studies has concentrated on the recovery of water from the Martian regolith, the effect of temperature on the ability to drill icy regolith must be precisely considered. Temperature fluctuations during the days and nights impose cyclic thermal stresses on the regolith's structure. This phenomenon alters the mechanical response of the regolith to drilling operations.

Underground, extraterrestrial outposts seem to be much safer than surface bases on Mars; however, their safety and functionality may decrease if the environmental variables, e.g., temperature, undergo large variations. As no drilling operation has reached the lowest 
depths on Mars, the effect of depth, overburden weight, temperature and outpost size must be evaluated from the standpoints of safety and stability.

Mineral mining on planetary bodies can greatly benefit space technologies. The vacuum condition, microgravity, lack of atmosphere and limitations related to fluid application on planetary bodies are the most serious challenges preventing the utilization of large-scale terrestrial mining machinery on potentially habitable planets such as Mars. In future, simulated terrestrial laboratories, small-scale mining machines such as loaders are proposed to be manufactured and their capability of cutting and transporting Martian regolith can be examined in the presence of such environmental challenges.

Space colonization requires a joint partnership among the different space agencies around the world. More collaborative projects are required to create synergies in the development of space technology. Moreover, governments should provide scientific institutions such as universities with further funds to develop their infrastructure and investigations on the geomechanics applicable in space.

Author Contributions: Conceptualization, formal analysis, data curation, writing-original draft preparation, writing—review and editing, visualization, resources, methodology, D.K. and M.A.M.Z.; validation, supervision, project administration, D.K.; software, investigation, M.A.M.Z. All authors have read and agreed to the published version of the manuscript.

Funding: This project was supported by the AGH University of Science and Technology, Krakow, Poland, subsidy 16.16.190.779.

Institutional Review Board Statement: Not applicable.

Informed Consent Statement: Not applicable.

Data Availability Statement: All relevant data are within the paper.

Conflicts of Interest: The authors of this paper declare no conflict of interest.

\section{References}

1. Cherkasov, I.I.; Shvarev, V.V. Soviet Investigations of the Mechanics of Lunar Soil. Soil Mech. Found. Eng. 1973, 10, 252-256. [CrossRef]

2. McSween, H.Y.; Taylor, G.J.; Wyatt, M.B. Elemental composition of the Martian crust. Science 2009, 324, 736-739. [CrossRef]

3. Schrunk, D.; Sharpe, B.; Cooper, B.; Thangavelu, M. The Moon: Resources, Future Development, and Settlement, 2nd ed.; SpringerPraxis: New York, NY, USA, 2007; ISBN 9780387360553.

4. Benaroya, H. Lunar habitats: A brief overview of issues and concepts. Reach 2017, 7-8, 14-33. [CrossRef]

5. Jablonski, A.M.; Showalter, D. An introduction to AIT requirements for lunar systems and structures. In Proceedings of the 15th Biennial International Conference on Engineering, Science, Construction, and Operations in Challenging Environments, Earth and Space, Orlando, FL, USA, 11 April 2016.

6. Wang, C.; Zeng, Z. Overview of Geomechanical Properties of Bakken Formation in Williston Basin. In Proceedings of the 45th U.S. Rock Mechanics/Geomechanics Symposium, San Francisco, CA, USA, 26-29 June 2011.

7. Benaroya, H.; Nagurka, M. Space structures: Issues in dynamics and control. J. Aerosp. Eng. 1990, 3, 251-270. [CrossRef]

8. Ettouney, M.; Benaroya, H.; Agassi, N. Cable structures and lunar environment. J. Aerosp. Eng. 1992, 5, 297-310. [CrossRef]

9. Benaroya, H. Tensile-integrity structures for the Moon. Appl. Mech. Rev. 1993, 46, 326-335. [CrossRef]

10. Malla, R.B.; Adib-Jahromi, H.R.; Accorsi, M.L. Simplified design method for braced double-skinned structure in lunar application. J. Aerosp. Eng. 1995, 8, 189-195. [CrossRef]

11. Aulesa, V.; Ruiz, F.; Casanova, I. Structural requirements for the construction of shelters on planetary surfaces. In Proceedings of the 7th International Conference and Exposition on Engineering, Construction, Operations, and Business in Space, Albuquerque, NM, USA, 27 February 2000; pp. 403-409. [CrossRef]

12. Ruess, F.; Schaenzlin, J.; Benaroya, H. Structural design of a lunar habitat. J. Aerosp. Eng. 2006, 19, 133-157. [CrossRef]

13. Malla, R.B.; Chaudhuri, D. Analysis of a 3D frame-Membrane structure for lunar base. In Proceedings of the 10th Biennial International Conference on Engineering, Construction, and Operations in Challenging Environments and Second NASA/ARO/ASCE Workshop on Granular Materials in Lunar and Martian Exploration, Houston, TX, USA, 5-6 March 2006; pp. 1-8. [CrossRef]

14. Faierson, E.J.; Logan, K.V.; Stewart, B.K.; Hunt, M.P. Demonstration of concept for fabrication of lunar physical assets utilizing lunar regolith simulant and a geothermite reaction. Acta Astronaut. 2010, 67, 38-45. [CrossRef]

15. Malla, R.B.; Gionet, T.G. Dynamic response of a pressurized frame-membrane lunar structure with regolith cover subjected to impact load. J. Aerosp. Eng. 2013, 26, 855-873. [CrossRef] 
16. Mottaghi, S.; Benaroya, H. Design of a lunar surface structure. II: Seismic structural analysis. J. Aerosp. Eng. $2015,28,04014053$. [CrossRef]

17. Klosky, J.L.; Sture, S.; Ko, H.Y.; Barnes, F. Helical anchors for combined anchoring and soil testing in lunar operations. In Proceedings of the 6th ASCE Specialty Conference and Exposition on Engineering, Construction, and Operations in Space, Albuquerque, NM, USA, 26-30 April 1998; pp. 489-494. [CrossRef]

18. Kömle, N.I.; Weiss, P.; Yung, K.L. Considerations on a suction drill for lunar surface drilling and sampling: I. Feasibility study. Acta Geotech. 2008, 3, 201-214. [CrossRef]

19. Chang, B.C.; Bernold, L.E.; Lee, T.S. Experimental study of lunar regolith anchoring forces. In Proceedings of the 12th Biennial International Conference on Engineering, Construction, and Operations in Challenging Environments, Honolulu, HI, USA, 14-17 March 2010; pp. 1418-1422. [CrossRef]

20. Ebert, T.; Larochelle, P. Simulation of soft regolith dynamic anchors for celestial exploration. In Proceedings of the 2016 IEEE Aerospace Conference, Big Sky, MT, USA, 30 June 2016; pp. 1-7. [CrossRef]

21. Stanley, S.; Dougherty, S.; Laramee, J. The Low-force Sample Acquisition System. In Proceedings of the NASA Science Technology Conference, Adelphi, MD, USA, 15 June 2007; pp. 1-15.

22. Ylikorpi, T.; Visentin, G.; Suomela, J. A robotic rover-based deep driller for Mars exploration. In Proceedings of the 35th Aerospace Mechanisms Symposium, Sunnyvale, CA, USA, 9-11 May 2001; pp. 185-196.

23. Coste, P.A.; Fenzi, M.; Eiden, M. A system for the challenging task of collecting samples from a comet surface. In Proceedings of the International Symposium Organized by the European Space Agency (5th ESMATS), Noordwijk, The Netherlands, 28-30 October 1992; pp. 137-142.

24. Zuber, M.T. The crust and mantle of Mars. Nature 2001, 412, 220-227. [CrossRef] [PubMed]

25. Tenzer, R.; Eshagh, M. The Sub-Crustal Stress Field in the Taiwan Region. Terr. Atmos. Ocean. Sci. 2015, 26, 261-268. [CrossRef]

26. Sjöberg, L.E. Solving Vening Meinesz-Moritz inverse problem in isostasy. Geophys. J. Int. 2009, 179, 1527-1536. [CrossRef]

27. Chicarro, A.F.; Schultz, P.H.; Masson, P. Global and regional ridge patterns on Mars. Icarus 1985, 63, 153-174. [CrossRef]

28. Watters, T.R. Compressional tectonism on Mars. JGR Planets 1993, 98, 17049-17060. [CrossRef]

29. Knapmeyer, M.; Oberst, J.; Hauber, E.; Wählisch, M.; Deuchler, C.; Wagner, R. Working models for spatial distribution and level of Mars' seismicity. JGR Planets 2006, 11, 1-23. [CrossRef]

30. Schultz, R.A.; Watters, T.R. Forward mechanical modeling of the Amenthes Rupes thrust fault on Mars. Geophys. Res. Lett. 2001, 28, 4659-4662. [CrossRef]

31. Watters, T.R. Elastic dislocation modeling of wrinkle ridges on Mars. Icarus 2004, 171, 284-294. [CrossRef]

32. Grott, M.; Hauber, E.; Werner, S.C.; Kronberg, P.; Neukum, G. Mechanical modeling of thrust faults in the Thaumasia region, Mars, and implications for the Noachian heatflux. Icarus 2007, 186, 517-526. [CrossRef]

33. Ruiz, J.; Fernández, C.; Gomez-Ortiz, D.; Dohm, J.M.; López, V.; Tejero, R. Ancient heat flow, crustal thickness, and lithospheric mantle rheology in the Amenthes region, Mars. EPSL 2008, 270, 1-12. [CrossRef]

34. Mueller, K.; Vidal, A.; Robbins, S.; Golombek, M.; West, C. Fault and fold growth of the Amenthes uplift: Implications for Late Noachian crustal rheology and heatflow on Mars. EPSL 2014, 408, 100-109. [CrossRef]

35. NASA Mars 2020 Rover Sample Collection Animation. Available online: https://mars.nasa.gov/mars2020/multimedia/videos/ ?v=423 (accessed on 6 February 2020).

36. Gladstone, G.R.; Hurley, D.M.; Retherford, K.D.; Feldman, P.D.; Pryor, W.R.; Chaufray, J.Y.; Versteeg, M.; Greathouse, T.K.; Steffl, A.J.; Throop, H.; et al. LRO-LAMP observations of the LCROSS impact plume. Science 2010, 330, 472-476. [CrossRef] [PubMed]

37. Sheshpari, M.; Fujii, Y.; Tani, Y. Underground structures in Mars excavated by tunneling methods for sheltering humans. Tunn. Undergr. Space Technol. 2017, 64, 61-73. [CrossRef]

38. Quosay, A.A.; Knez, D. Sensitivity Analysis on Fracturing Pressure using Monte Carlo Simulation Technique. Oil Gas Eur. Mag. 2016, 42, 140-144.

39. Quosay, A.A.; Knez, D.; Ziaja, J. Hydraulic Fracturing: New Uncertainty Based modelling Approach for Process Design Using Monte Carlo Simulation Technique. PLoS ONE 2020, 15, e0236726. [CrossRef]

40. Jaumann, R.; Hiesinger, H.; Anand, M.; Crawford, I.A.; Wagner, R.; Sohl, F.; Jolliff, B.L.; Scholten, F.; Knapmeyer, M.; Hoffmann, H.; et al. Geology, geochemistry, and geophysics of the Moon: Status of current understanding. Planet. Space Sci. 2012, 74, 15-41. [CrossRef]

41. Wilhelms, D.E.; McCauley, J.F.; Trask, N.J. The geologic history of the Moon. USGS 1987, 19, 283-292. [CrossRef]

42. Head, J.W., III; Wilson, L. Lunar mare volcanism—stratigraphy, eruption conditions, and the evolution of secondary crusts. Geochim. Cosmochim. Acta 1992, 56, 2155-2175. [CrossRef]

43. Hiesinger, H.; Head, J.W., III. New views of lunar geoscience: An introduction and overview. Rev. Mineral. Geochem. 2006, 60, 1-81. [CrossRef]

44. Wieczorek, M.A.; Phillips, R.J. The "Procellarum KREEP Terrane": Implications for mare volcanism and lunar evolution. J. Geophys. Res. 2000, 105, 20417-20430. [CrossRef]

45. Jolliff, B.L.; Gillis, J.J.; Haskin, L.A.; Korotev, R.L.; Wieczorek, M.W. Major lunar crustal terranes. Surface expressions and crust-mantle origins. J. Geophys. Res. 2000, 105, 4197-4216. [CrossRef]

46. Schubert, G.; Lingenfelter, R.E.; Peale, S.J. The morphology, distribution, and origin of lunar sinuous rilles. Rev. Geophys. 1970, 8 , 199-224. [CrossRef] 
47. Hurwitz, D.M.; Head, J.W.; Wilson, L.; Hiesinger, H. Origin of lunar sinuous rilles: Modeling effects of gravity, surface slope, and lava composition on erosion rates during the formation of Rima Prinz. J. Geophys. Res. 2012, 117, E12. [CrossRef]

48. Ahrens, T.J.; Rubin, A.M. Impact-induced tensional failure in rock. J. Geophys. Res. 1993, 98, 1185-1203. [CrossRef]

49. Oberst, J.; Mizutani, H. A New Inventory of Deep Moonquake Nests Visible in the Apollo 12 Area. In Proceedings of the Lunar and Planetary Science Conference Abstracts, Houston, TX, USA, 11-15 March 2002; pp. 1704-1705.

50. Nakamura, Y. Farside deep Moonquakes and deep interior of the Moon. J. Geophys. Res. 2005, 110, E1. [CrossRef]

51. Fa, W. Simulation for Ground Penetrating Radar (GPR) Study of the Subsurface Structure of the Moon. Appl. Geophys. 2013, 99, 98-108. [CrossRef]

52. Lucey, P.G.; Korotev, R.L. Understanding the lunar surface and space-Moon interactions. Rev. Mineral. Geochem. 2006, 60, 83-219. [CrossRef]

53. Colwell, J.E.; Batiste, S.; Hora'nyi, M.; Robertson, S.; Sture, S. Lunar surface: Dust dynamics and regolith mechanics. Rev. Geophys. 2007, 45, 1-26. [CrossRef]

54. Papike, J.; Taylor, L.; Simon, S. Lunar Minerals, in Lunar Sourcebook: A User's Guide to the Moon; Cambridge Univ. Press: New York, NY, USA, 1991; ISBN 978-0521334440.

55. Jaffe, L.D. Surface structure and mechanical properties of the Lunar maria. JGR 1967, 72, 1727-1731. [CrossRef]

56. Nordmeyer, E.F. Lunar Surface Mechanical Properties Derived from Track Left by Nine Meter Boulder. In MSC Intern. Note Books; 67-TH-1; NASA: Washington, DC, USA, 1967; pp. 1-10.

57. Scott, R.F.; Roberson, F.I. Soil Mechanics Surface Sampler: Lunar surface tests, results, and analyses. JGR 1968, 73, 4045-4080. [CrossRef]

58. Moore, H.J. Estimates of the Mechanical Properties of Lunar Surface Using Tracks and Secondary Impact Craters Produced by Blocks and Boulders; US Dept. of the Interior, Geological Survey: Herndon, VA, USA, 1970. [CrossRef]

59. Hovland, H.J.; Mitchell, J.K. Mechanics of Rolling Sphere-Soil Slope Interaction; Space Sciences Laboratory, University of California: Berkeley, CA, USA, 1970.

60. Costes, N.C.; Carrier, W.D.; Mitchell, J.K.; Scott, R.F. Apollo 11: Soil mechanics results. J. Soil Mech. Found. Div. 1970, 96, 2045-2080. [CrossRef]

61. Costes, N.C.; Cohron, G.T.; Moss, D.C. Cone penetration resistance test-an approach to evaluating the in-place strength and packing characteristics of Lunar soils. In Proceedings of the 2nd Lunar Science Conference, Houston, TX, USA, 31 March 1971; pp. 1973-1987.

62. Mitchell, J.K.; Bromwell, L.G.; Carrier, W.D., III; Costes, N.C.; Houston, W.N.; Scott, R.F. Soil Mechanics Experiment, Apollo 14 Preliminary Science Report; NASA: Washington, DC, USA, 1971; pp. 87-108.

63. Mitchell, J.K.; Carrier, W.D.; Houston, W.N.; Scott, R.F.; Bromwell, L.G.; Durgunoglu, H.T.; Hovland, H.J.; Treadwell, D.D.; Costes, N.C. Soil Mechanics, Apollo 16 Preliminary Science Report; NASA SP-315; NASA: Washington, DC, USA, 1972; Volume 8, pp. 1-29.

64. Watters, T.; McGovern, P.; Irwin Iii, R. Hemispheres Apart: The Crustal Dichotomy on Mars. Annu. Rev. Earth Planet. Sci. 2007, 35, 621-652. [CrossRef]

65. McEwen, A.; Malin, M.; Carr, M.; Hartmann, W. Voluminous volcanism on early Mars revealed in Valles Marineris. Nature 1999, 397, 584-586. [CrossRef]

66. Baker, V. Water and the Martian landscape. Nature 2001, 412, 228-236. [CrossRef] [PubMed]

67. Fairén, A.G.; Dohm, J.M.; Baker, V.R.; de Pablo, M.A.; Ruiz, J.; Ferris, J.C.; Anderson, R.C. Episodic flood inundations of the northern plains of Mars. Icarus 2003, 165, 53-67. [CrossRef]

68. Zuber, M.T.; Solomon, S.C.; Phillips, R.J.; Smith, D.E.; Tyler, G.L.; Aharonson, O.; Balmino, G.; Banerdt, W.B.; Head, J.W.; Johnson, C.L.; et al. Internal Structure and Early Thermal Evolution of Mars from Mars Global Surveyor Topography and Gravity. Science 2000, 287, 1788-1793. [CrossRef]

69. Neumann, G.A.; Zuber, M.T.; Wieczorek, M.A.; McGovern, P.J.; Lemoine, F.G.; Smith, D.E. Crustal structure of Mars from gravity and topography. J. Geophys. Res. 2004, 2004JE002262, 1-18. [CrossRef]

70. Stevenson, D.J. Mars' core and magnetism. Nature 2001, 412, 214-219. [CrossRef]

71. Rossi, A.P.; Gasselt, S.V. Geology of Mars after the first 40 years of exploration. Res. Astron. Astrophys. 2010, 10, 621-652. [CrossRef]

72. Seidelmann, P.K.; Abalakin, V.K.; Bursa, M.; Davies, M.E.; de Bergh, C.; Lieske, J.H.; Oberst, J.; Simon, J.L.; Standish, E.M.; Stooke, P.; et al. Celestial Mechanics and Dynamical Astronomy. Celest. Mech. Dyn. Astron. 2002, 82, 83-110. [CrossRef]

73. Williams, D.; Greeley, R.; Fergason, R.L.; Kuzmin, R.; McCord, T.B.; Combe, J.P.; Head, J.W., III; Xiao, L.; Manfredi, L.; Poulet, F.; et al. The Circum-Hellas Volcanic Province, Mars: Overview. Planet. Space Sci. 2009, 57, 895-916. [CrossRef]

74. Baker, V.; Maruyama, S.; Dohm, J. Superplumes: Beyond Plate Tectonics; Springer: Dordrecht, The Netherlands, 2007; pp. 507-523. ISBN 978-1-4020-5750-2.

75. Carr, M. Formation of Martian flood features by release of water from confined aquifers. J. Geophys. Res. 1979, 84, 2995-3007. [CrossRef]

76. Delage, P.; Karakostas, F.; Dhemaied, A.; Belmokhtar, M.; Lognonné, P.; Golombek, M.; Banerdt, B. An Investigation of the Mechanical Properties of Some Martian Regolith Simulants with Respect to the Surface Properties at the InSight Mission Landing Site. Space Sci. Rev. 2017, 211, 191-213. [CrossRef] 
77. Rvidson, R.E.; Bellutta, P.; Calef, F.; Fraeman, A.A.; Garvin, J.B.; Gasnault, O.; Wiens, R.C. Terrain physical properties derived from orbital data and the first 360 sols of Mars Science Laboratory Curiosity rover observations in Gale Crater. JGR Planets 2014, 119, 1322-1344. [CrossRef]

78. Spohn, T.; Grott, M.; Müller, N.; Knollenberg, J.; Krause, C.; Hudson, T.; Deen, R.; Marteau, E.; Golombek, M.; Hurst, K.; et al. Mars Regolith Properties as Constrained from HP3 Mole Operations and Thermal Measurements. In Proceedings of the EGU General Assembly, Vienna, Austria, 4-8 May 2020. [CrossRef]

79. Moore, H.J.; Clow, G.D.; Hutton, R.E. A summary of Viking sample-trench analyses for angles of internal friction and cohesions. J. Geophys. Res. 1982, 87, 10043-10050. [CrossRef]

80. Moore, H.J.; Bickler, D.B.; Crisp, J.A.; Eisen, H.J.; Gensler, J.A.; Haldemann, A.F.; Matijevic, J.R.; Reid, L.K.; Pavlics, F. Soil-like deposits observed by Sojourner, the Pathfinder rover. J. Geophys. Res. 1999, 104, 8729-8746. [CrossRef]

81. Kalapodis, K.; Kampas, G.; Ktenidou, O.J. A review towards the design of extraterrestrial structures: From regolith to human outposts. Acta Astronautica. 2020, 175, 540-569. [CrossRef]

82. Parness, A. Anchoring Foot Mechanisms for Sampling and Mobility in Microgravity. In Proceedings of the 2011 IEEE International Conference on Robotics and Automation, Shanghai, China, 9-13 May 2011. [CrossRef]

83. Knez, D. Stress State Analysis in Aspect of Wellbore Drilling Direction. J. Arch. Min. Sci. 2014, 59, 71-76. [CrossRef]

84. Metzger, P.; Li, X.; Immer, C.; Lane, J. ISRU implications for lunar and Martian plume effects. In Proceedings of the 47th AIAA Aerospace Sciences Meeting including the New Horizons Forum and Aerospace Exposition, Orlando, FL, USA, 5-8 January 2009.

85. Lee, J.; Chang, B.C.; Lee, S.; Lee, T.S. Feasibility study on lunar concrete landing pad. In Proceedings of the 13th ASCE Aerospace Division Conference on Engineering, Science, Construction, and Operations in Challenging Environments, and the 5th NASA/ASCE Workshop on Granular Materials in Space Exploration, Pasadena, CA, USA, 11 July 2012. [CrossRef]

86. Tsytovich, N.A. The Mechanics of Frozen Ground (McGraw-Hill Series in Modern Structures); McGraw-Hill Inc.: New York, NY, USA, 1975; ISBN 978-0070654105.

87. Gorevan, S.P.; Myrick, T. Rock abrasion tool: Mars Exploration Rover Mission. J. Geophys. Res. 2003, 108, E12. [CrossRef]

88. Bar-Cohen, Y.; Zacny, K. Drilling in Extreme Environments: Penetration and Sampling on Earth and Other Planets; Wiley: Hoboken, NJ, USA, 2009; ISBN 9783527626632.

89. Chu, P.; Wilson, J.; Davis, K.; Shiraishi, L.; Burke, K. Icy soil acquisition device for the 2007 Phoenix Mars Lander. In Proceedings of the 39th Aerospace Mechanisms Symposium, Huntsville, AL, USA, 7-9 May 2008; pp. 289-302.

90. Peters, G.H.; Mungas, G.S.; Bearman, G.H.; Beegle, L.W.; Smith, J.A. RASP sample acquisition on the Phoenix Mars Scout Mission. In Proceedings of the 38th Lunar and Planetary Science Conference, (Lunar and Planetary Science XXXVIII), Houston, TX, USA, 12-16 March 2007.

91. Gromov, V.V.; Misckevich, A.V.; Yudkin, E.N.; Kochan, H.; Coste, P.; Re, E. The mobile penetrometer, a mole for sub-surface soil investigation. In Proceedings of the 7th European Space Mechanisms and Tribology Symposium, Noordwijk, The Netherlands, 1-3 October 1997.

92. Chang, S.S.F.; Bone, G.M. Burr size reduction in drilling by ultrasonic assistance. Robot Comput. Integr. Manuf. 2005, 21, 442-450. [CrossRef]

93. Neugebauer, R.; Stoll, A. Ultrasonic application in drilling. J. Mater. Process. Technol. 2004, 149, 633-639. [CrossRef]

94. Liu, C.S.; Zhao, B.; Gao, G.F.; Zhang, X.H. Study on ultrasonic vibration drilling of particulate reinforced aluminum matrix composites. Key Eng. Mater. 2005, 291-292, 447-452. [CrossRef]

95. Babitsky, V.I.; Astashev, V.K.; Meadows, A. Vibration excitation and energy transfer during ultrasonically assisted drilling. J. Sound Vib. 2007, 308, 805-814. [CrossRef]

96. Maurer, W.C. Novel Drilling Techniques; Pergamon Press: New York, NY, USA, 1968; ISBN 978-0080036151.

97. Bar-Cohen, Y.; Sherrit, S.; Dolgin, B.P.; Bao, X.; Chang, Z.; Pal, D.S.; Krahe, R.; Kroh, J.; Du, S.; Peterson, T. Ultrasonic/sonic drilling/coring (USDC) for planetary applications. In Proceedings of the SPIE's 7th Annual International Symposium on Smart Structures and Materials, Newport Beach, CA, USA, 5-8 March 2001. [CrossRef]

98. Bao, X.; Bar-Cohen, Y.; Chang, Z.; Dolgin, B.P.; Sherrit, S.; Pal, D.S.; Du, S.; Peterson, T. Modeling and computer simulation of ultrasonic/sonic driller/corer (USDC). IEEE Trans. Ultrason. Ferroelectr. Freq. Control 2003, 50, 1147-1160. [CrossRef]

99. Badescu, M.; Sherrit, S.; Olorunsola, A.; Aldrich, J.; Bao, X.; Bar-Cohen, Y.; Chang, Z.; Doran, P.T.; Fritsen, C.H.; Kenig, F.; et al. Ultrasonic/sonic gopher for subsurface ice and brine sampling: Analysis and fabrication challenges, and testing results. In Proceedings of the SPIE Smart Structures and Materials Symposium, San Diego, CA, USA, 30 March 2006. [CrossRef]

100. Sherrit, S.; Bar-Cohen, Y.; Badescu, M.; Bao, X.; Chang, Z.; Jones, C.; Aldrich, J. Compact non-pneumatic powder sampler (NPPS). In Proceedings of the NASA New Technology Report NTR, Pasadena, CA, USA, 23 February 2006.

101. Chang, Z.; Sherrit, S.; Bao, X.; Bar-Cohen, Y. Design and analysis of ultrasonic horn for USDC (ultrasonic/sonic driller/corer). In Proceedings of the SPIE Smart Structures and Materials Symposium, San Diego, CA, USA, 15-18 March 2004. [CrossRef]

102. Badescu, M.; Stroescu, S.; Sherrit, S.; Aldrich, J.; Bao, X.; Bar-Cohen, Y.; Chang, Z.; Hernandez, W.; Al-Shawi, I. Rotary hammer ultrasonic/sonic drill system. In Proceedings of the IEEE International Conference on Robotics and Automation, Pasadena, CA, USA, 19-23 May 2008; pp. 602-607. [CrossRef]

103. Bar-Cohen, Y.; Randolph, J.; Ritz, C.; Cook, G.; Bao, X.; Sherrit, S. Sample Preparation, Acquisition, Handling and Delivery (SPAHD) System using the Ultrasonic/Sonic Driller/Corer (USDC) with Interchangeable Bits. In Proceedings of the NASA New Technology Report (NTR), Pasadena, CA, USA, 1 May 2002. 
104. Sims, M.R.; Sykes, J.; Stevenson, T.; Wiercigroch, M.; Parnell, J.; Hole, M. Design of an ultrasonic rock corer for use in planetary missions. In Proceedings of the ESTEC, Noordwijk, The Netherlands, 6 April 2002.

105. Sullivan, T.; Koenig, E.; Knudsen, C.; Gibson, M. Pneumatic conveying of materials at partial gravity. J. Aerosp. Eng. 1994, 7, 199-208. [CrossRef]

106. Blacic, J.D.; Rowley, J.C.; Cort, G.E. Surface drilling technologies for Mars. NASA Marshall Space Flight Cent. Manned Mars Mission. 1986, 1, 1-4.

107. Knez, D.; Khalilidermani, M. A Review of Different Aspects of Off-Earth Drilling. Energies 2021, 14, 7351. [CrossRef]

108. Rahmann, S.S.; Chilingarian, G.V. Casing Design-Theory and Practice, 1st ed.; Elsevier Science: Amsterdam, The Netherlands, 1995; ISBN 9780080528601.

109. Paulsen, G.; Zacny, K.; Chu, P.; Mumm, E.; Davis, K.; Frader, S.T.; Petrich, K.; Glaser, D.; Bartlett, P.; Cannon, H.; et al. Robotic drill systems for planetary exploration. In Proceedings of the AIAA Space, San Jose, CA, USA, 19-21 September 2006. [CrossRef]

110. Guerrero, J.L.; Reiter, J.W.; Rumann, A.; Wu, D.; Wang, G.Y.; Meyers, M.; Craig, J.; Abbey, W.; Beegle, L.W. Robotic drilling technology and applications to future space missions. In Proceedings of the 2006 American Geophysical Union Conference, Washington, DC, USA, 11-15 December 2006.

111. Khalilidermani, M.; Knez, D.; Zamani, M.A.M. Empirical Correlations between the Hydraulic Properties Obtained from the Geoelectrical Methods and Water Well Data of Arak Aquifer. Energies 2021, 14, 5415. [CrossRef]

112. Knez, D.; Rajaoalison, H. Discrepancy between Measured Dynamic Poroelastic Parameters and Predicted Values from Wyllie's Equation for Water-Saturated Istebna Sandstone. Acta Geophys. 2021, 69, 673-680. [CrossRef]

113. Wolfe, L.H.; Thieme, J.O. Physical and Thermal Properties of Frozen Soil and Ice. In Proceedings of the Annual SPE Fall Meeting, New Orleans, LA, USA, 6-9 October 1963; pp. 67-72. [CrossRef]

114. Rajaoalison, H.; Knez, D.; Zlotkowski, A. Changes of Dynamic Mechanical Properties of Brine-Saturated Istebna Sandstone under Action of Temperature and Stress. Przemyst Chem. 2019, 98, 801-804.

115. Sommariva, A.; Gori, L.; Chizzolini, B.; Pianorsi, M. The economics of moon mining. Acta Astronaut. 2020, 170, 712-718. [CrossRef]

116. Horneck, G.; Facius, R.; Reitz, G.; Rettberg, P.; Khan, B.C.; Gerzer, R. Critical issues in connection with human planetary missions: Protection of and from the environment. Acta Astronautica. 2001, 49, 279-288. [CrossRef]

117. Podnieks, E.R.; Siekmeier, J.A. Lunar surface mining equipment study. In Proceedings of the 3rd International Engineering, Construction, and Operations in Space III, Denver, CO, USA, 31 May-4 June1992; pp. 1104-1115.

118. Schrnk, D.; Sharpe, B.; Cooper, B.; Thangavelu, M. The Moon, Resources, Future Development and Colonization; Wiley: New York, NY, USA, 1999; ISBN 978-0-387-73982-3.

119. Knez, D.; Calicki, A. Looking For a New Source of Natural Proppants in Poland. J. Bull. Pol. Acad. Sci. Tech. Sci. 2018, 66, 3-8. [CrossRef]

120. Knez, D.; Mazur, S. Simulation of Fracture Conductivity Changes due to Proppant Composition and Stress Cycles. J. Pol. Miner. Eng. Soc. 2019, 2, 231-234.

121. Knez, D.; Wiśniowski, R.; Owusu, W.A. Turning Filling Material into Proppant for Coalbed Methane in Poland-Crush test results. Energies 2019, 12, 1820. [CrossRef]

122. Zamani, M.A.M.; Knez, D. A new mechanical-hydrodynamic safety factor index for sand production prediction. Energies 2021, 14, 3130. [CrossRef]

123. Knez, D.; Zamani, M.A.M. Empirical Formula for Dynamic Biot Coefficient of Sandstone Samples from South-West of Poland. Energies 2021, 14, 5514. [CrossRef]

124. Cox, R.M. Fragmentation of lunar rock with explosives. In Proceedings of the 7th International Conference and Exposition on Engineering, Construction, Operations, and Business in Space, Albuquerque, NM, USA, 27 February-2 March 2000; pp. 805-812. [CrossRef]

125. Skvarekova, E.; Wittenberger, G.; Senova, A.; Bakalar, T.; Harcarufka, R. An innovative process for efficient data evaluation in an atmospheric geochemical survey of contaminated soil. Civ. Environ. Eng. Rep. 2020, 30, 173-187. [CrossRef] 